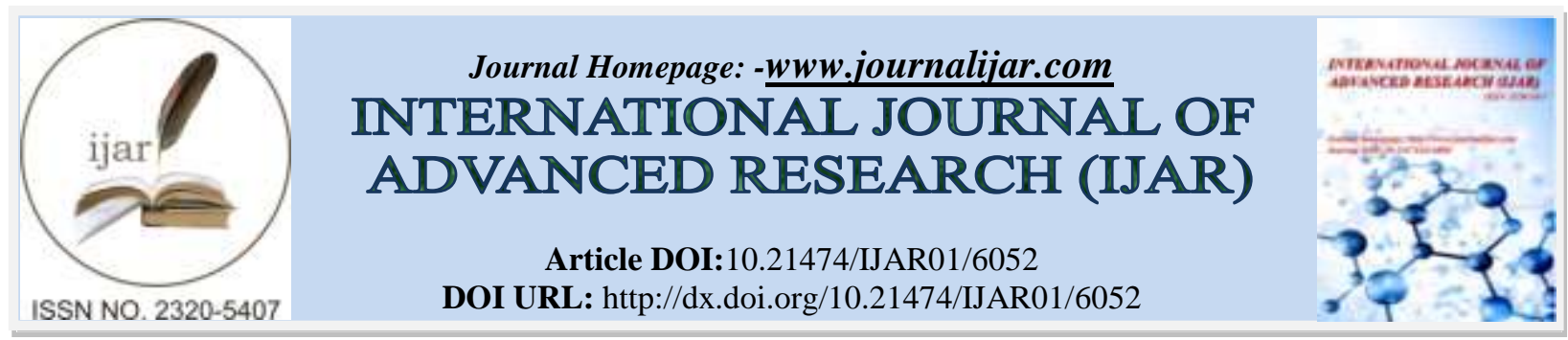

RESEARCH ARTICLE

\title{
EXPRESSION OF CD105 AND CD31 IN BENIGN AND MALIGNANT SALIVARY GLAND TUMORS WITH MYOEPITHELIAL DIFFERENTIATION (A COMPARATIVE STUDY).
}

\section{Nadia Fathy Hassabou ${ }^{1}$, Rehab Fawzi Kasem ${ }^{2}$, Heba Ahmed Farag ${ }^{3}$ and Nahed Emad El-Din Abo Azma ${ }^{4}$}

1. Assistant Lecturer, Oral Pathology Department, Faculty of Dentistry, October 6 University, Egypt.

2. Assistant Professor, Oral and Maxillofacial Pathology Department, Faculty of Dentistry, Cairo University, Egypt.

3. Professor, Oral and Maxillofacial Pathology Department, Faculty of Dentistry, Cairo University, Egypt

4. Professor, Oral Pathology Department, Faculty of Dentistry, Tanta University, Egypt.

\section{Manuscript Info}

\section{Manuscript History}

Received: 13 October 2017

Final Accepted: 15 November 2017

Published: December 2017

\section{Key words:-}

Angiogenesis, microvessel density (MVD), endothelial cells (ECs), CD105, CD31, salivary gland tumors (SGTs).

\begin{abstract}
Background and Aim: One of the strongest prognostic factors in tumor grading is tumor neovasculature. Hence, angiogenesis is an important target to eliminate tumor growth and metastasis. This study was carried out with the aim of evaluating the angiogenesis in salivary gland tumors by assessing microvessel density (MVD) using CD105 and CD31. This work also compared and correlated the expressions of both markers in benign and malignant salivary gland tumors (SGTs) and in grades of malignant tumors with myoepithelial differentiation.

Material and Methods: The material of this work consisted of 76 paraffin embedded specimens including 20 benign tumors and 48 malignant tumors with different grades and types and 8 non neoplastic salivary gland tissues.

Immunohistochemical staining was performed using both primary mouse monoclonal CD31 and CD105 antibodies for assessment of angiogenesis.

Results: All studied cases showed positive CD31 and CD105 immunoreactivity. The study revealed a highly significant increase of CD31-MVD and CD105-MVD in malignant SGTs compared to benign tumors. Also, high grade malignancy demonstrated an increase in MVD when compared to low grade malignancy. In addition, malignant SGTs without myoepithelial cell differentiation showed significantly higher values of CD31-MVD and non significant difference of CD105-MVD compared to those containing myoepithelial cells. CD31-MVD values were always higher than CD105 in all studied cases.

Conclusion: CD105 was more accurate in the assessment of tumor angiogenesis compared to the most commonly used CD31 panendothelial marker.
\end{abstract}

Copy Right, IJAR, 2017,. All rights reserved.
Corresponding Author:-Nadia Fathy Hassabou. Address:-Assistant lecturer, Oral Pathology Department, Faculty of Dentistry, October 6 University, Egypt. 


\section{Introduction:-}

Tumor cells release growth factors that stimulate proliferation and migration of endothelial cells (ECs) to form a new irregular network of vessels that provides nutrients and oxygen that promote tumor cell proliferation, tumor progression and development of distant metastasis (Weidner, 2000 and Sebti and Hamilton, 2000).

Regulatory mechanisms in angiogenesis are physiologically governed by a homeostatic balance between positive and negative angiogenic regulators, so that neovascularization is normally suppressed (Duff et al., 2003 and Reinmuth et al., 2003).

Microvessel density (MVD) is an important factor which reflects tumor angiogenesis and is considered as a potential prognostic marker in numerous tumors (Duff et al., 2007).

MVD is a good indicator of therapeutic efficacy, as there is a positive correlation between MVD and tumor recurrence. Also, it is an important marker to determine the prognosis in many human malignancies as the survival rate decreases with increased MVD (Nico et al., 2008).

CD105 is a 180 kilodalton $(\mathrm{kDa})$ phosphorylated transmembrane glycoprotein, its gene is located on chromosome 9. CD105 is a component of TGF- $\beta$ receptor complex which is mainly expressed on active immature endothelial cells (ECs) (Fonsatti et al., 2000 and Dallas et al., 2008). Consistently, higher levels of CD105 expression are detected on human microvascular ECs in tissues undergoing active angiogenesis, such as inflamed and regenerating tissues or tumors (Wong et al., 2000 and Chung et al., 2004).

It is reported that CD105 is an essential factor for ECs proliferation which promotes activation of angiogenesis (Goumans et al., 2003). Moreover, CD105 expression is a prominent feature of newly formed tumor vessels with minimum expression in old preexisting ones (Fonsatti et al., 2003 and Duff et al., 2003).

CD105 is considered a potential predictor for prognosis in different solid malignancies by assessment of neovascularization through measuring MVD during progressive stages of carcinogenesis (Akagi et al., 2002).

CD31 is an integral membrane protein of $130 \mathrm{kDa}$, also known as platelet endothelial cell adhesion molecule-1 (PECAM-1). It is one member of the immunoglobulin gene superfamily, which is expressed on adult and embryonic ECs but it is rarely expressed on leukocytes and platelets. Also, CD31 mediates cell to cell adhesion (DeLisser et al., 1997). It is reported that anti-CD31 has the ability to stain large and small vessels with equal intensity in normal and neoplastic tissues. However, CD31 strongly cross reacts with plasma cells and other inflammatory cells which may obscure the assessment of microvessels in tumors with a prominent plasma cellular infiltration (DeYoung, 1993).

Since scarce studies have focused on expression of CD105 in salivary gland tumors (SGTs), this study was aimed to evaluate angiogenesis using CD105 in comparison to CD31, and to correlate the expressions of both markers in benign and malignant SGTs and in grades of malignant tumors with myoepithelial differentiation.

\section{Material and Methods:-}

Selection of Tissue Specimens:-

Sixty-eight specimens of SGTs were retrieved from the archival paraffin blocks from files of the Oral and Maxillofacial Pathology Department, Faculty of Dentistry, Cairo University. The specimens comprised 20 specimens of adenoid cystic carcinoma (AdCCs), including 7 cribriform patterns, 7 tubular patterns and 6 solid patterns, 20 specimens of mucoepidermoid carcinoma (MECs), including 11 low grade and 9 high grade cases, 8 specimens of carcinoma ex pleomorphic adenoma (Ca ex PA), 10 specimens of pleomorphic adenoma (PA) and 10 specimens of Warthin's tumors.

Eight specimens of non neoplastic salivary gland tissues were obtained as a control group from the resected tumor margins. The study has been carried out under The Code of Ethics of the World Medical Association (Declaration of Helsinki) for experiments involving humans. The study was approved by the ethical committee of the Faculty of Dentistry, Cairo University. 


\section{Histopathological Examination:-}

Three sections from each paraffin block were cut at $4 \mu \mathrm{m}$ thickness. One section was examined using H\&E stain in order to confirm the previously made diagnosis, while the other two tissue sections were used in the immunohistochemical study.

\section{Immunohistochemistry:-}

De-paraffinization and re-hydration was performed by a slide stainer Varistain Gemini (ThermoShendon, United Kingdom). Then, sections were washed with distilled water and heated in TRIS/EDTA buffer (pH 9.0) for 8 minutes at $110^{\circ} \mathrm{C}$ in a microwave.

After blocking the endogenous peroxidase activity, all slides were incubated in the primary antibody. Both primary mouse monoclonal CD105 antibody (clone: SN6h, isotype: $\operatorname{IgG} 1 / \kappa$, ready to use) and primary mouse monoclonal CD31 antibody (clone: JC/70A, isotype: $\operatorname{IgG} 1 / \kappa$, ready to use) were supplied by Thermo Fisher Scientific Anatomical Pathology, Lab Vision, USA code no. \# MS-1290 -R7 and code no. \# MS-353-R7, respectively).

\section{Evaluation of MVD:-}

According to the method previously described by Weidner et al., slides stained with anti-CD105 antibody and antiCD31 antibody within each tumor were examined by light microscope at a magnification of (x100) in areas of neovascularization containing the highest number of capillaries "hot spots" in five randomly selected microscopic fields (Weidner et al., 1991).

Immunohistochemical results were interpreted by two observers at magnification (x200). Single intratumoral endothelial cells or clusters of endothelial cells positive for CD105 and CD31 were considered as a single countable microvesssel while, peritumoral blood vessels and vessels characterized by thick muscular walls or with wide lumen greater than $20 \mu \mathrm{m}$ in diameter were ignored and excluded from the counting. Then images of each of these selected microscopic fields were photo documented using the Leica Q550 IW Imaging Workstation and Leica Qwin cell manual counting software.

\section{Statistical Analysis:-}

Scores of overall CD105 and CD31 expression were represented as mean values and standard deviation using SPSS (Statistical Package for Social Sciences) 10.3 software. One way analysis of variance test (ANOVA) and Student's ttests were used to compare the mean values between the groups. P-value was considered highly significant when $\leq$ 0.01 and significant when $\leq 0.05$.

\section{Results:-}

Positive immunostaining for both markers was observed in all studied cases as cytoplasmic brown pigments in ECs of blood vessels. In non-neoplastic salivary tissue, few blood vessels showed weak positive expression of CD31 and CD105 with a mean MVD value of $2.2 \pm 0.74$ and $1.8 \pm 0.74$, respectively.

Immunopositivity of CD31 was noticed indiscriminately in large blood vessels with wide lumina as well as small vessels with non specific reaction of neoplastic cells, while CD105 reaction was observed only in the newly formed tortuous small blood vessels without lumina or with narrow lumina which less than $20 \mu \mathrm{m}$ in diameter with negative staining of the large ones.

In Warthin's tumors, positive staining was highly obvious in the blood vessels within the lymphoid tissues with a mean CD31-MVD value of 3.6 \pm 0.8 and CD105-MVD 2.8 \pm 0.748 .

All cases of PA showed positive immunoreactivity in the blood vessels in the cell rich areas between sheets of myoepithelial cells, while less positive vessels were detected in myxoid and chondroid tissues for both CD31 and CD105 (fig. $1 \mathrm{a \& b}$ ) with mean MVD value of $3.1 \pm 0.78$ and $2.1 \pm 0.489$, respectively. The increase was non significant in Warthin's tumors compared to PA $(\mathrm{p}=0.2430)$.

In malignant SGTs, the immuno-expression of CD31 and CD105 showed a highly significant increase in the mean value of MVD in high grade MECs in relation to low grade ones ( $\mathrm{p}=0.002$ and 0.05 , respectively). The positive vessels in AdCCs were frequently arranged adjacent to the carcinomatous aggregates. The MVDs assessed by CD31 
and CD105 antibodies were significantly higher in solid pattern than these of the tubular and cribriform patterns (fig. $2 \mathrm{a \& b})(\mathrm{p}=0.013$ and 0.002 , respectively).

The mean value of CD31-MVD and CD105-MVD showed a highly significant increase in Ca ex PA, compared to benign PA (fig. $3 \mathrm{a} \& b)(\mathrm{p}=0.001$ and 0.0001 , respectively).

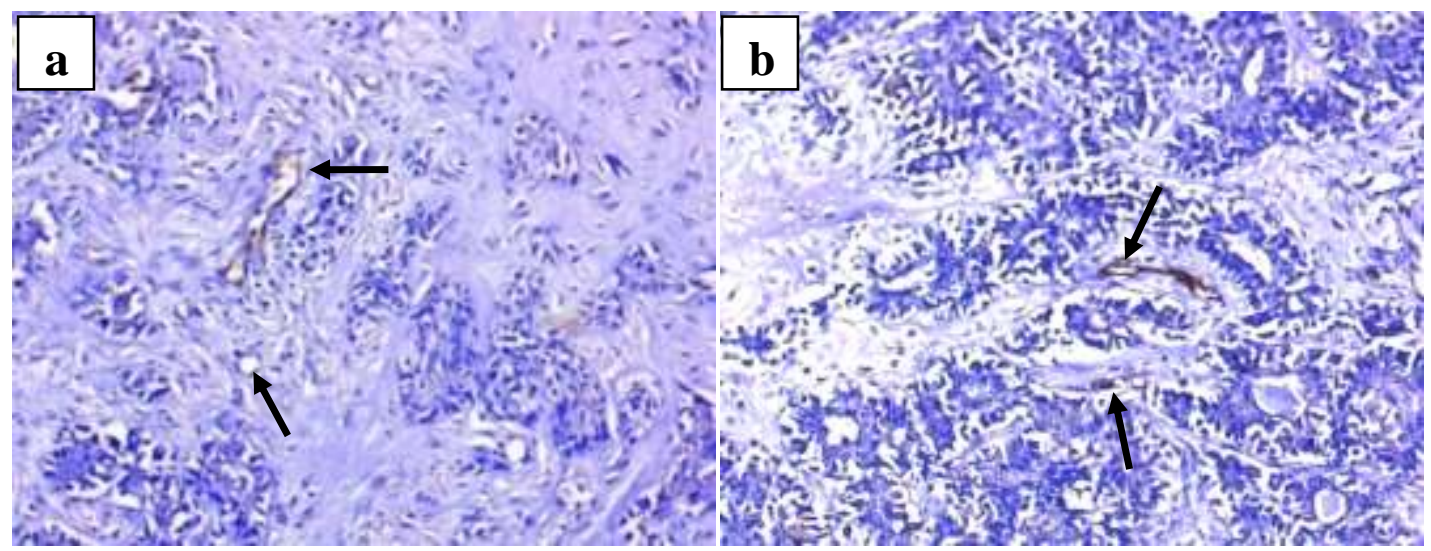

Figure (1a\&b):- Pleomorphic adenoma showing positive blood vessels in the cell rich areas between sheets of myoepithelial cells. (a) CD31 positive blood vessels (anti-CD31antibody x200). (b) CD105 positive small and narrow vessels (anti-CD105 antibody x200).

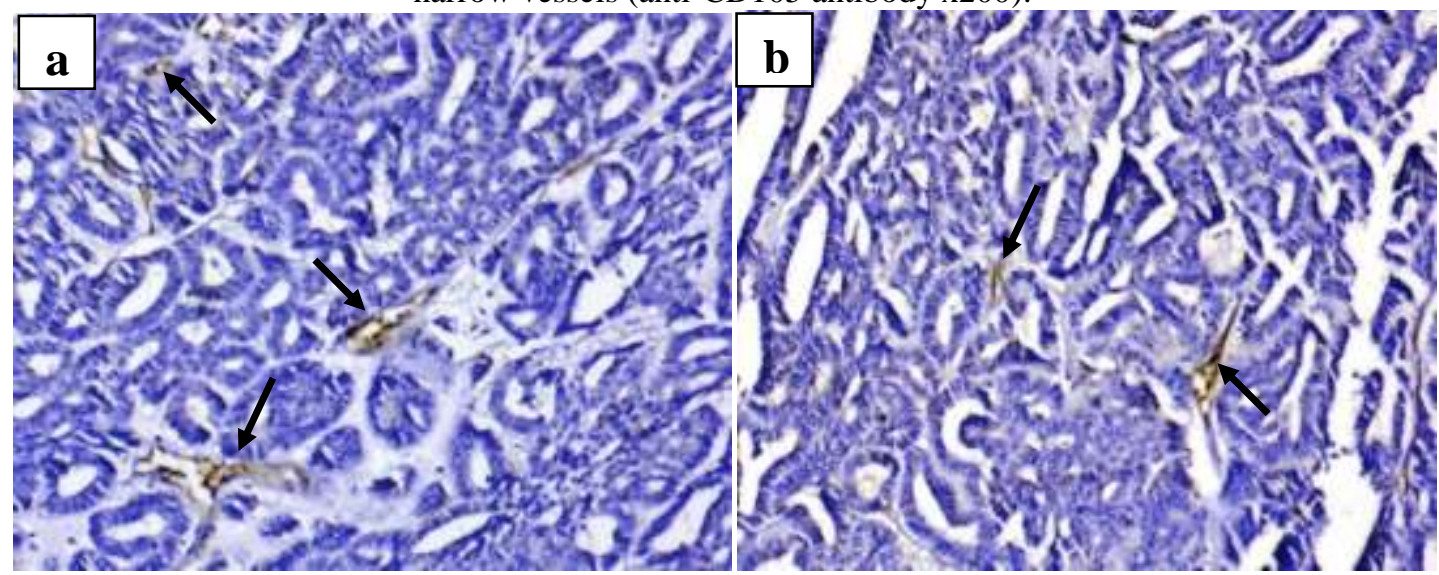

Figure ( $\mathbf{2} \mathbf{a \& b})$ :- Tubular pattern of AdCC showing positive vessels that are frequently arranged adjacent to the carcinomatous aggregates. (a) CD31 positive blood vessels (anti-CD31 antibody x200). (b) CD105 positive blood vessels (anti CD105 antibody x200).

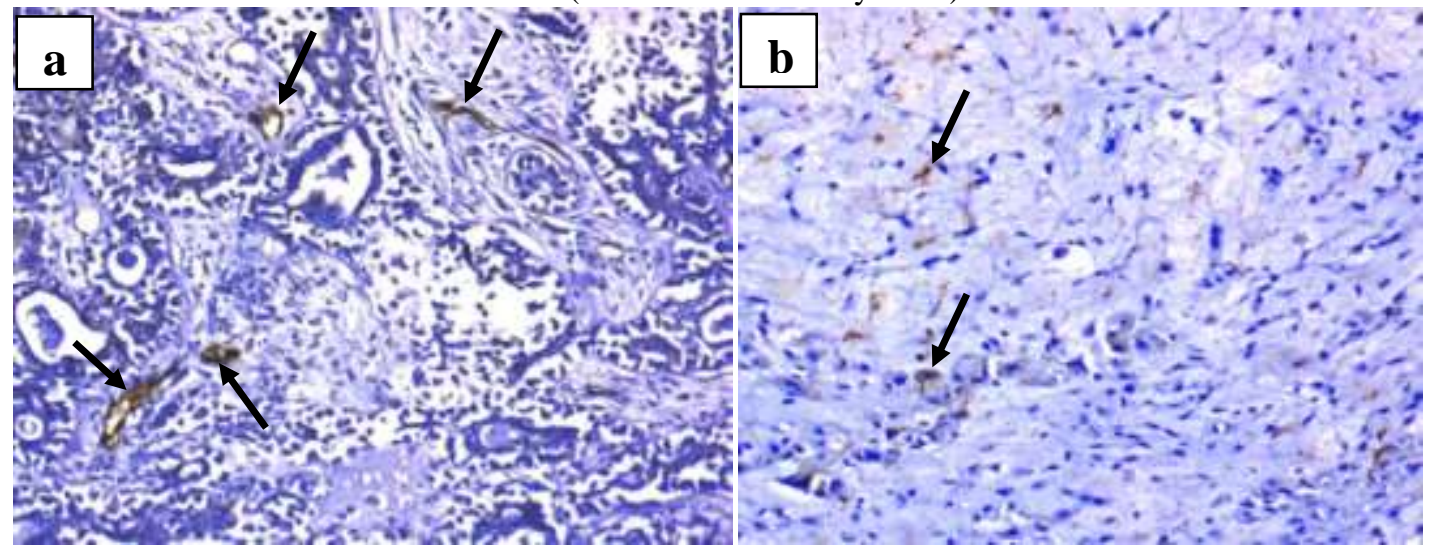

Figure (3 a\&b):- Carcinoma ex-pleomorphic adenoma showing positive blood vessels. (a) Dilated as well as small CD31 positive vessels (anti-CD31 antibody x200). (b) Numerous CD105 positive capillary sprouts (anti-CD105 antibody x200). 
Although malignant SGTs showed the highest mean values of MVD, it was observed that salivary gland carcinomas containing myoepithelial cells (AdCCs and Ca ex PA) showed lower mean values than those without myoepithelial cells (MECs) which is statistically significant for CD31 $(\mathrm{p}=0.01)$ while no statistical difference was revealed with CD105 ( $\mathrm{p}=0.189)$, (table 1, graph 1).

It was revealed that the malignant tumors of all studied cases had higher significant increase in the mean value of MVD in comparison to benign tumors and non-neoplastic salivary gland tissues that was $(\mathrm{p}=0.00001)$ for both markers, (table 1, graph 2).

Table 1:-Mean values of MVD measured by CD31 and CD105 in myoepithelial and non myoepithelial carcinomas, non neoplastic salivary gland tissues, benign and malignant SGTs.

\begin{tabular}{|c|c|c|c|c|c|}
\hline Marker & $\begin{array}{c}\text { Myoepithelial } \\
\text { Carcinoma }\end{array}$ & $\begin{array}{c}\text { Non } \\
\text { myoepithelial } \\
\text { Carcinoma }\end{array}$ & $\begin{array}{c}\text { Non neoplastic } \\
\text { salivary gland } \\
\text { tissues }\end{array}$ & Benign SGTs & Malignant SGTs \\
\hline \multirow[t]{3}{*}{ CD31 } & $\begin{array}{c}\text { Mean } \pm \text { SD }= \\
8.2 \pm 1.46\end{array}$ & $\begin{array}{c}\text { Mean } \pm \text { SD }= \\
12.6 \pm 2.86\end{array}$ & $\begin{array}{c}\text { Mean } \pm \text { SD } \\
2.2 \pm 0.74\end{array}$ & $\begin{array}{c}\text { Mean } \pm \text { SD } \\
3.8 \pm 0.8\end{array}$ & $\begin{array}{l}\text { Mean } \pm \text { SD } \\
10.72 \pm 0.84\end{array}$ \\
\hline & \multicolumn{2}{|c|}{$\mathrm{t}=3.33336$} & \multicolumn{3}{|c|}{$\mathrm{f}=49.1208$} \\
\hline & \multicolumn{2}{|c|}{$\mathrm{p}=0.01 *$} & \multicolumn{3}{|c|}{$\mathrm{p}=0.00001^{* *}$} \\
\hline \multirow[t]{3}{*}{ CD105 } & $\begin{array}{c}\text { Mean } \pm \text { SD }= \\
5.8 \pm 1.11\end{array}$ & $\begin{array}{c}\text { Mean } \pm \text { SD }= \\
6.5 \pm 1.28\end{array}$ & $\begin{array}{c}\text { Mean } \pm \text { SD } \\
1.8 \pm 0.78\end{array}$ & $\begin{array}{c}\text { Mean } \pm \text { SD } \\
2.7 \pm 0.64\end{array}$ & $\begin{array}{c}\text { Mean } \pm \text { SD } \\
6 \pm 1\end{array}$ \\
\hline & \multicolumn{2}{|c|}{$\mathrm{t}=0.89722$} & \multicolumn{3}{|c|}{$f=61.9187$} \\
\hline & \multicolumn{2}{|c|}{$\mathrm{p}=0.189449$ (N.S) } & \multicolumn{3}{|c|}{$\mathrm{p}=0.00001^{* *}$} \\
\hline
\end{tabular}

\footnotetext{
*Significant

**Highly significant

N.S: Non significant
}

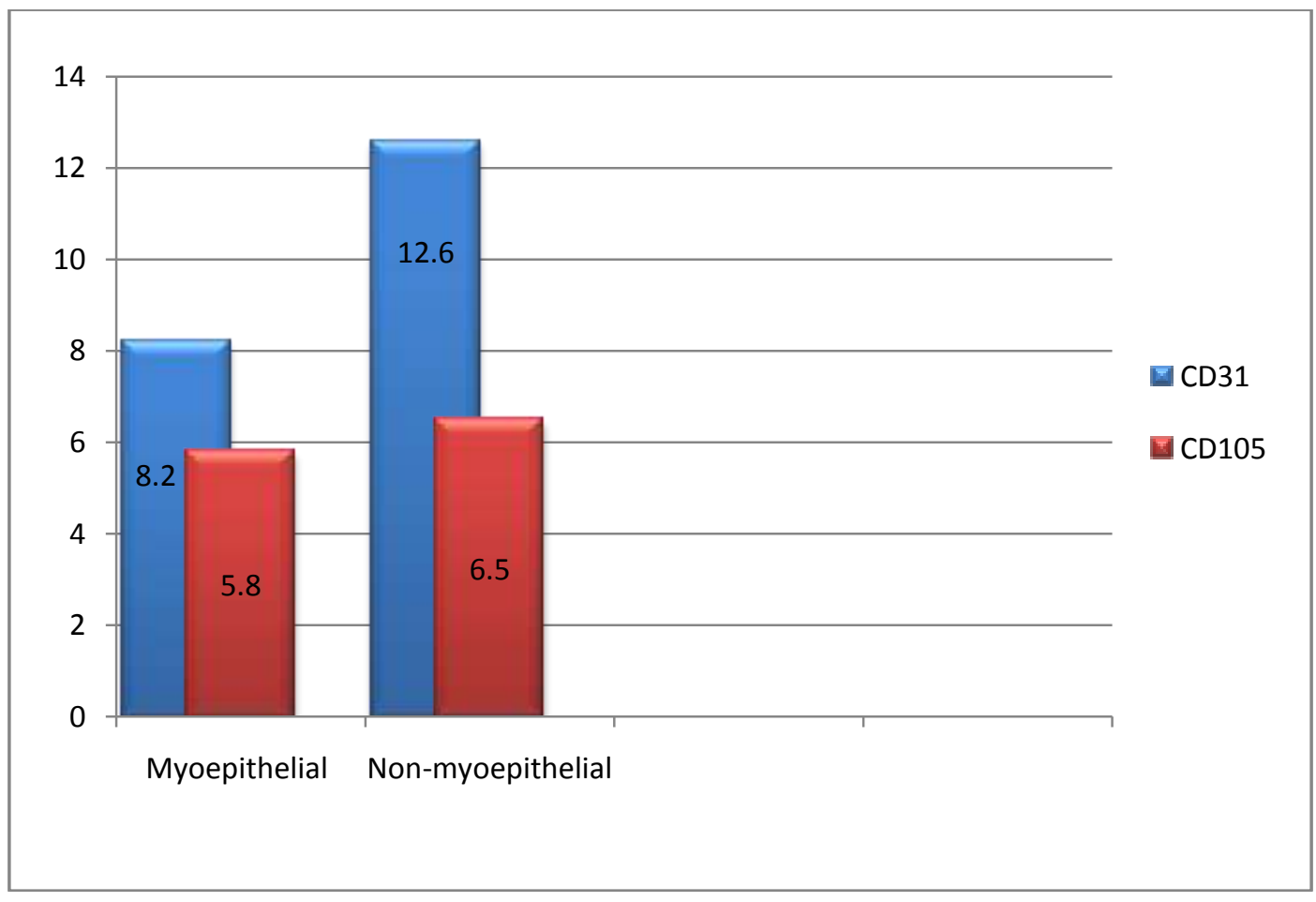

Graph 1:-Mean values of MVD in myoepithelial and non myoepithelial carcinomas. 


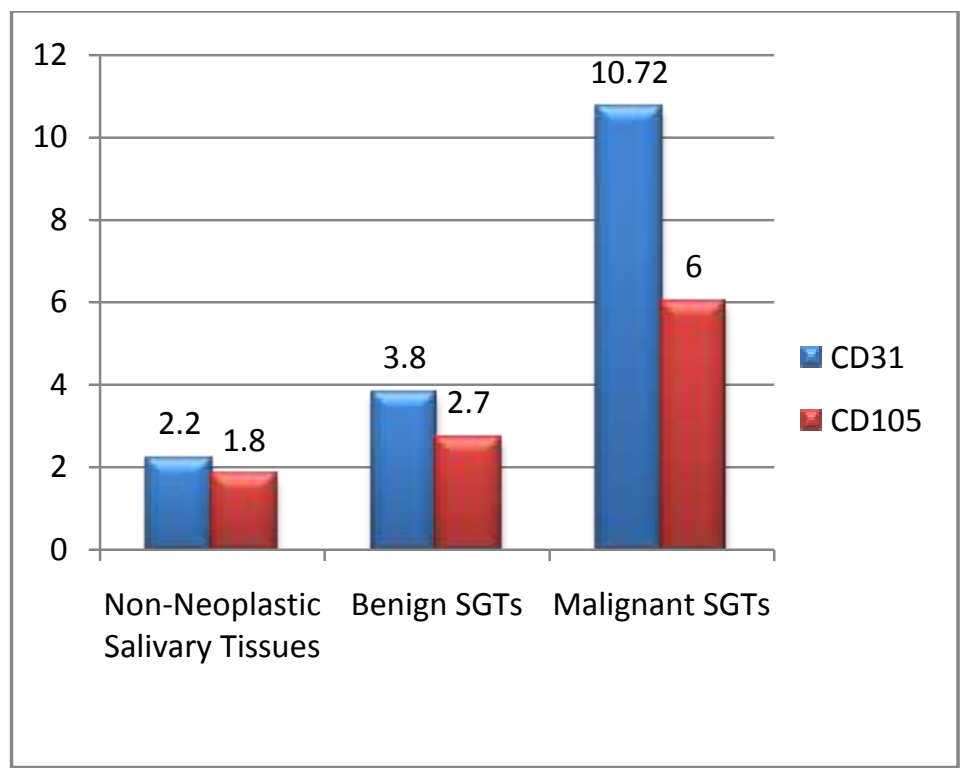

Graph 2:-Mean values of MVD in non-neoplastic salivary gland tissues, benign and malignant SGTs

\section{Discussion:-}

Malignant SGTs constitute a major challenge in head and neck oncology because of its low frequency, variation in histological types, difficult surgical approach and poor response to therapy. Therefore, the present study was conducted to evaluate the quantification of angiogenesis in SGTs by measuring the MVD, since it is considered as an important prognostic factor which significantly associates with overall survival and correlates with the grades of malignancy (Cardoso et al., 2009).

In the present study, positive CD31 and CD105 immunoexpression was detected in all tissue sections obtained from benign and malignant SGTs, as well as non neoplastic salivary gland tissues that have been used asa control group which showed few weak positive blood vessels.

The immunoreactivity in non neoplastic salivary tissues may be attributed to marked upregulation of CD31 and CD105 in ECs of inflamed tissues with an associated inflammatory cell infiltrate, thus reflecting the activation of angiogenesis in tissues which may be subjected to inflammatory stimuli (Pusztaszeri et al., 2006 amd Rossi et al., 2013). From this point, the current findings can be explained by the development of angiogenic activity in non neoplastic salivary gland tissues which may be subjected to inflammatory stimuli.

Moreover, in the current work, it was noticeable that CD31 was expressed in both small and large vessels with equal intensity. Also, occasionally the cell membrane and cytoplasm of tumor cells revealed weak positive expression. This comes in the same context with the results of (Saad et al., 2005 and Mitselou et al., 2016) who observed that CD31 was not specific for ECs due to its expression in the tumor cells as well as staining of all the blood vessels indiscriminately between the newly formed small vessels and the large old preexisting ones. This is in contrast to CD105, which appeared specifically in the tumor vessels being of small caliber, tortuous, with or without clear lumina reflecting active angiogenesis, while it showed no staining of stromal or tumor cells. These observations reflect that most of the microvessels positive for CD105 are considered to be proliferating ECs which sprouted from the larger microvessels.

As regards the expression of CD31 and CD105 in different benign SGTs, it was observed that MVD measured in Warthin's tumors was higher compared to that in PA. This may be attributed to the inhibitory role of myoepithelial cells which constitute the main cells of origin of PA due to secreting high levels of angiogenic inhibitors as thrombospondin-1 and maspin while they express low levels of angiogenic growth factors such as VEGF which play a crucial role in the regulation of blood vessel formation (Teymoortash et al., 2007 and Soares et al., 2015). Furthermore, the higher MVD in Warthin's tumors may be explained by the study of (Rabia et al., 2015) who 
concluded that the oncocytic epithelium of the tumor may enhance the hyperplasia of lymphoid tissue which induces tumor angiogenesis.

Moreover, it was noted that positive immunoreactivity was detected in the cell rich areas of PA. This could be attributed to the diversity of the stroma, in which high vascularization is not required in myxoid and chondroid areas in contrast to cell rich areas that requiring more oxygen in order to support the metabolic demands (Soares et al., 2015).

It was observed that MVD of both markers was much higher in malignant SGTs when compared to MVD count in benign tumors. These findings are in line with previous observations of (Cardoso et al., 2009 and Moghadam et al., 2015) who reported that salivary gland carcinomas demonstrated higher increase in the formation of blood vessels than benign tumors. Thus, the present and the previous findings prove that the development of new blood vessels is essential for clonal expansion which reflects higher rate of neovascularization and invasiveness of malignant SGTs (Sharma et al., 2005).

Significant correlation between MVD and tumor grades was observed in both markers as it was found that high grade MECs had higher MVD compared to low grade tumors reflecting that angiogenesis increased in parallel with increasing tumor grade. Moreover, it was observed that measured MVD significantly increased with increasing the tumor grade in AdCC from tubular and cribriform to solid pattern which showed the highest level of MVD.

These current observations were fully consistent with (Moghadam et al., 2015) who observed higher MVD in high grade malignant tumors during assessment of angiogenesis for different types of SGTs. This can be explained by the reports of (Sharma et al., 2005) who proposed that the main factor affecting the density of blood vessels is the metabolic needs of tumor cells which usually increase with tumor progression.

As regard to measured CD31-MVD and CD105-MVD, our study showed that the malignant SGTs without myoepithelial cell differentiation (MECs) showed significant increase in measured MVD than those containing myoepithelial cells (AdCCs and Ca ex PA).

In the same context are the results of previous studies which revealed the highest levels of MVD in MECs in comparison to those of AdCCs (Costa et al., 2008; Tadbir et al., 2012; Dhanuthai et al., 2013 and Moghadam et al., 2015). Thus, MVD analysis was found to be influenced by the presence of myoepithelial cells which secrete high levels of angiogenic inhibitors but express very low levels of angiogenic factors (Dallas et al., 2008 and Dhanuthai et al., 2013).

As regards CD31 and CD105 immunostaining, the results of the current work showed that CD31-MVD was always significantly higher than CD105-MVD in all studied cases of benign and malignant SGTs as well as the residual non neoplastic salivary gland tissues.

This is based on the fact that CD105 is predominantly active and specifically reacts with proliferating ECs in tissues undergoing angiogenesis with no or weak staining of blood vessels within normal tissues. This is explained by its high affinity to bind TGF- $\beta$ which is considered one of the most important proteins involved in angiogenesis and is highly expressed in immature ECs. This is in contrast to other panendothelial markers which are not specific, not only because they are not expressed in ECs, but because they also react with neoplastic as well as with stromal cells (Nassiri et al., 2011 and Tadbir et al., 2012).

\section{Conclusion:-}

From the previous studies and the current work, it can be concluded that CD105 gives more accurate measures of the tumor angiogenic activity and reduces false positive staining of blood vessels when compared with the commonly used CD31 panendothelial marker.

\section{Acknowledgement:-}

We would like to thank all the members of the Research Centers in Faculty of Dentistry, Cairo University and in the Faculty of Dentistry, October University for Modern Sciences and Arts (MSA) for the facilities they provided to the authors during the course of this work. 


\section{Conflict of interest:-}

All the authors declare that they have no conflict of interest.

\section{References:-}

1. Akagi K., Ikeda Y., Sumiyoshi Y., Kimura Y., Kinoshita J., Miyazaki M., et al. (2002): Estimation of angiogenesis with anti-CD105 immunostaining in the process of colorectal cancer development. Surgery, 131(1 Suppl): S109-13.

2. Cardoso S., Souza K., Faria P., Eisenberg A., Dias F., Loyola A. (2009): Assessment of angiogenesis by CD105 antigen in epithelial salivary gland neoplasms with diverse metastatic behavior. BMC Cancer; 9: 391.

3. Chung Y., Hou Y., Pan A. (2004): Endoglin (CD105) expression in the development of haemorrhoids. Eur J Clin Invest; 34:107-12.

4. Costa A., Demasi A., Bonfitto V., Bonfitto J., Furuse C., Araújo V., et al. (2008): Angiogenesis in salivary carcinomas with and without myoepithelial differentiation. Virchows Arch; 453: 359-67.

5. Dallas N., Samuel S., Xia L., Fan F., Gray M., Lim S., et al. (2008): Endoglin (CD105): a marker of tumor vasculature and potential target for therapy. Clin Cancer Res; 14: 1931-37.

6. DeLisser H., Christofidou-Solomidou M., Strieter R., Burdick M., Robinson C., Wexler R., et al. (1997): Involvement of endothelial PECAM-1/CD31 in angiogenesis. Am J Pathol; 151: 671-77.

7. DeYoung B., Wick M., Fitzgibbon J., Sirgi K., Swanson P. (1993): CD31: An immunospecific marker for endothelial differentiation in human neoplasms. Appl Immunol; 1: 97-100.

8. Dhanuthai K., Sappayatosok K., Yodsanga S., Rojanawatsirivej S., Pausch N., Pitak-Arnnop P. (2013): An analysis of microvessel density in salivary gland tumours: A single centre study. Surgeon; 11 (3): 147- 52.

9. Duff S., Jeziorska M., Kumar S., Haboubi N., Sherlock D., O'Dwyer S., et al. (2007): Lymphatic vessel density, microvessel density and lymphangiogenic growth factor expression in colorectal cancer. Colorectal Dis; 9:793-800.

10. Duff S., Li C., Garland J., Kumar S. (2003): CD105 is important for angiogenesis: evidence and potential applications. FASEB J; 17(9): 984-92.

11. Fonsatti E., Altomonte M., Nicotra M., Natali P., Maio M. (2003): Endoglin (CD105): a powerful therapeutic target on tumor-associated angiogenetic blood vessels. Oncogene; 22 (42):6557-63.

12. Fonsatti E., Jekunen A., Kairemo K., Coral S., Snellman M., Nicotra M., et al. (2000): nEndoglin is a suitable target for efficient imaging of solid tumors: in vivo evidence in a canine mammary carcinoma model. Clin Cancer Res; 6: 2037-43.

13. Goumans M., Lebrin F., Valdimarsdottir G. (2003): Controlling the angiogenic switch: a balance between two distinct TGF-b receptor signaling pathways. Trends Cardiovasc Med; 13 (7):301-07.

14. Mitselou A., Galani V., Skoufi U., Arvanitis D., Lampri E., Loachim E. (2016): Syndecan-1, EpithelialMesenchymal Transition Markers (E-cadherin/ $\beta$-catenin) and Neoangiogenesis-related Proteins (PCAM-1 and Endoglin) in Colorectal Cancer. Anticancer Res; 36: 2271-80.

15. Moghadam S., Abadi A., Mokhtari S. (2015): Immunohistochemical analysis of CD34 expression in salivary gland tumors. J Oral MaxillofacPathol; 19 (1): 30-33.

16. Nassiri F., Cusimano M., Scheithauer B., Rotondo F., Fazio A., Yousef G., et al. (2011): Endoglin (CD105): a review of its role in angiogenesis and tumor diagnosis, progression and therapy. Anticancer Res; 31(6): 228390.

17. Nico B., Benagiano V., Mangieri D., Maruotti N., Vacca A., Ribatti D. (2008): Evaluation of microvascular density in tumors: pro and contra. Histol Histopathol; 23: 601-07.

18. Pusztaszeri M., Seelentag W., Bosman F. (2006): Immunohistochemical Expression of Endothelial Markers CD31, CD34, von Willebrand Factor and Fli-1 in Normal Human Tissues. J Histochem Cytochem.; 54 (4): 385-95.

19. Rabia A., Ebru L., Tuba K., Didar G., Gulhan O., Cengiz O. (2015): Warthin's tumor: An unknown pathogenesis: A neoplasm or a reactive hyperplasia? Indian J Pathol Microbiol.; 58 (1): 7-11.

20. Reinmuth N., Parikh A., Ahmad S., Liu W., Stoeltzing O., Fan F., et al. (2003): Biology of angiogenesis in tumors of the gastrointestinal tract. Microsc Res Tech; 60:199-207.

21. Rossi E., Sanz-Rodriguez F., Eleno N., Düwell A., Blanco F., Langa C., et al. (2013): Endothelial endoglin is involved in inflammation: role in leukocyte adhesion and transmigration. Blood ; 121 (2):403-15.

22. Saad R., EL-Gohary Y., Memari E., Liu Y., Silverman J. (2005): Endoglin (CD105) and vascular endothelial growth factor as prognostic markers in esophageal adenocarcinoma. Hum Pathol; 36, 955-61. 
23. Sebti S., Hamilton A. (2000): Design of growth factor antagonists with antiangiogenic and antitumor properties. Oncogene; 19: 6566-73.

24. Sharma S., Sharma M., Sarkar C. (2005): Morphology of angiogenesis in human cancer: a conceptual overview, histoprognostic perspective and significance of neoangiogenesis. Histopathology; 46 (5):481-89.

25. Soares A., Altemani A., de Oliveira T., de Oliveira Fonseca Rodrigues F., Silva A., Soave D., et al. (2015): Comparison of the Blood and Lymphatic Microvessel Density of Pleomorphic Adenoma and Basal Cell Adenoma. Clin Med Insights Pathol; 8: 17-21.

26. Tadbir A., Pardis S., Ashkavandi Z., Najvani A., Ashraf M., Taheri A., et al. (2012): Expression of Ki67 and CD105 as proliferation and angiogenesis markers in salivary gland tumors. Asian Pac J Cancer Prev; 13: 515559.

27. Teymoortash A., Schrader C., Shimoda H., Kato S., Werner J. (2007): Evidence of lymphangiogenesis in Warthin's tumor of the parotid gland. Oral Oncol; 43(6):614-18.

28. Weidner N. (2000): Angiogenesis as a predictor of clinical outcome in cancer patients. Human Pathol; 31(4):403-05.

29. Weidner N., Semple J., Welch W., Folkman J. (1991): Tumor angiogenesis and metastasis correlation in invasive breast carcinoma. N Engl J Med; 324:1-8.

30. Wong S., Hamel L., Chevalier S., Philip A. (2000): Endoglin expression on human microvascular endothelial cells association with beta glycan and formation of higher order complexes with TGF-beta signalling receptors. Eur J Biochem; 267: 5550-60. 